\title{
Difficult intubation
} and brain-stem anaesthesia

Chidambaram Ananthanarayan MD FRCPC, A.F.D. Cole MD FRCPC, Martin Kazdan MD FRCSC

Purpose: To present a case of difficult intubation with brainstem anaesthesia after retrobulbar block with bupivacaine and lidocaine and sedation with midazolam and to point out that close monitoring and timely treatment is important in preventing an unfavourable outcome.

Clinical features: An 82-yr-old man with treated hypertension and stable angina was scheduled for cataract extraction. Physical examination revealed a class 2 airway. He had a retrobulbar block after topical tetracaine drops, with bupivacaine $0.5 \%$ and lidocaine $2 \%$ with hyaluronidase under sedation with $1 \mathrm{mg}$ midazolam. Five minutes after the block, respiration slowed, he became unresponsive and oxygen saturation decreased to $80 \%$. Immediate ventilation with mask without additional oxygen improved saturation. Attempted tracheal intubation failed: the epiglottis could not be visualized despite flaccid jaw and extremeties. A laryngeal mask ainway was placed which was leaking and adequate ventilation could not be achieved but a second laryngeal mask airway was placed successfully.

Conclusion: This case emphasizes the need for close monitoring and personnel capable of managing the difficult ainway when intra-orbital anaesthesia is used.

Objectif : Présenter un cas d'intubation difficile avec anesthésie accidentelle du tronc cérébral consécutive à un bloc rétrobulbaire à la bupivacaine et à la lidocaine avec sédation au midazolam en mettant l'accent sur l'importance du monitorage et d'un traitement opportun dans le but de prévenir une complication désastreuse.

Éléments cliniques : Un angineux stable de 82 ans et hypertendu sous traitement était programmé pour une extraction de cataracte. L'examen physique révélait des voies aériennes de classe 2 . Après une anesthésie de contact à la tétracaine, il recevait un bloc rétrobulbaire à la bupivacaïne $0,5 \%$ et à la lidocaine $2 \%$ associées à de l'hyaluronidase sous sédation avec $1 \mathrm{mg}$ de midazolam. Cinq minutes après le block, la respiration ralentissait, il devenait inconscient et la saturation en oxygène tombait à $80 \%$. La ventilation immédiate au masque sans oxygène permettait d'améliorer la saturation. Une tentative d'intubation échouait, l'épiglotte r'étant pas visualisée malgré la flaccidité de la mâchoire et des extrémités. Un masque laryngé était inséré mais à cause d'un manque d'étanchéité, il était impossible de ventiler. On réussissait finalement à insérer un autre masque laryngé fonctionnel.

Conclusion : Cette observation souligne la nécessité d'un monitorage nigoureux et d'un personnel capable de prendre charge de voies aériennes difficiles quand une anesthésie intraorbitale est administrée.

From the Department of Anacsthesia and Department of Ophthalmology, Mount Sinai Hospital, University of Toronto, 600 University Avenue, Toronto, Ontario, M5G 1 X5.

Address correspondence to: Dr. Chidambaram Ananthanarayan, Phone: 416-586-5270, Fax: 416-586-8664.

Accepted for publication March 9, 1997. 
B RAIN-STEM anaesthesia is an uncommon but well-recognized complication of intraorbital regional anaesthesia. ${ }^{1}$ We present such a case, where the anaesthetic management was complicated by a coincidental anatomical variation in the patient's airway anatomy rendering tracheal intubation difficult or impossible by conventional laryngoscopic methods. The case is presented to highlight choices in management, and to discuss its implications for safe anaesthetic practice.

\section{Case report}

An 82-yr-old man, weighing $62 \mathrm{~kg}$, scheduled for cataract extraction and lens implantation under retrobulbar anaesthesia with monitored anaesthesia care, was seen in the pre-operative anaesthesia assessment clinic. Medical history revealed stable angina pectoris and treated hypertension. Medications included amlodipine, atenolol, and isosorbide dinitrate. Physical examination showed a blood pressure of $160 / 70 \mathrm{mmHg}$ and heart rate of $78 \mathrm{bpm}$. Assessment of the airway, including modified Mallampati score, ${ }^{2-6}$ mouth opening, ${ }^{7}$ cervical spine mobility, ${ }^{8-11}$ and thyromental distance ${ }^{5,12}$ revealed no abnormality. Quantitative assessment was only applied to the Samsoon modification of the Mallampati score (Class II), while the other variables were qualitatively unremarkable.

The patient arrived in the operating room, having taken his regular medications with less than $20 \mathrm{ml}$ water three hours before surgery. Routine monitoring (automatic blood pressure cuff, ECG, pulse oximetry) was instituted. He was moderately anxious. The blood pressure was $160 / 90 \mathrm{mmHg}$, heart rate $78 \mathrm{bpm}$, and oxygen saturation $97 \%$. An intravenous line was established, and two increments of $0.5 \mathrm{mg}$ midazolam iv were administered. Ten minutes after arrival, the patient was alert but calm, and haemodynamically stable, with oxygen saturation of $96 \%$. Retrobulbar block was performed by the surgeon using a mixture of $2 \mathrm{ml}$ bupivacaine $0.5 \%$ and $2 \mathrm{ml}$ lidocaine $2 \%$, with $0.4 \mathrm{ml}$ Wydase ${ }^{\circledR}$ (hyaluronidase) added. A further $6.6 \mathrm{ml}$ of the same mixture were used for facial nerve block.

Over the next five minutes, the patient became progressively more obtunded, his respiratory rate initially slowed, then he progressed from exclusively diaphragmatic breathing to apnea and unconsciousness. Oxygen saturation decreased to $\mathbf{8 0}$. Effective positive pressure ventilation was established by mask with $\mathrm{F}_{1} \mathrm{O}_{2}=1.0$, facilitated with an oropharyngeal airway. ( $\mathrm{SpO}_{2}$ increased immediately to $97 \%$.) A laryngeal mask airway but the cuff proved to have a large leak and it was subsequently removed. Tracheal intubation proved unexpectedly impossible, as only the very tip of the epiglottis could be visualized, despite the complete relaxation of the patient.

Another laryngeal mask was obtained and inserted, the cuff inflated, and ventilation established without difficulty. At this point, examination showed both pupils dilated and unresponsive to light. The blood pressure was $110 / 60 \mathrm{mmHg}$, heart rate $60 \mathrm{bpm}$ and $\mathrm{SpO}_{2}$ 97\%. Mechanical ventilation was continued for 20 min, until satisfactory spontaneous ventilation was re-established. After a further ten minutes, the patient was awake. With recovery of consciousness, contralateral pupillary reaction was restored. The patient had no lasting sequelae from his presumed brain-stem anaesthesia.

\section{Discussion}

This patient presented with progressive loss of consciousness and respiratory depression requiring ventilatory support. This was diagnosed as brain-stem anaesthesia and was complicated by difficult intubation.

The differential diagnosis included drug-induced unconsciousness and apnea. The small dose of midazolam, complete muscle relaxation and the presence of a contralateral dilated pupil (the blocked eye is invariably completely mydriatic) excluded systemic drug effect as the cause. The risk of brain stem anaesthesia with retrobulbar local anaesthesia has been estimated as 16 in $6000(0.27 \%)$ by Nicoll et al. ${ }^{13}$ Brain stem anaesthesia is considered to be due to loss of brain stem function due to the presence of local anaesthetic in the cerebro-spinal fluid, hence the term "brainstem anaesthesia."14-15

The mechanism by which intra-orbital local anaesthetic arrives in the cerebro-spinal fluid is not clear. Direct injection through the dural sheath surrounding the optic nerve, involving needle penetration of the sheath, has been the generally accepted mechanism. ${ }^{1}$ For this reason, it has been suggested that avoidance of Atkinson's position (the eye. gazing medially and upward) and the use of peri-bulbar rather than retrobulbar injections should minimize or eliminate the risk of sub-perineural injection of the optic nerve and consequent brain stem anaesthesia. ${ }^{16}$

However, Mandelcorn et al., ${ }^{17}$ drawing the analogy with spinal epidural anaesthesia, suggested that any intra-orbital local anaesthetic may diffuse through the dural sleeve of the optic nerve and, hence, track centrally into the cerebro-spinal fluid causing brain stem anaesthesia even when the optic nerve has not been directly penetrated by the needle. The importance of this suggestion is that local anaesthetic techniques 
such as peribulbar and sub-tenons injection although perhaps less likely to produce brain stem anaesthesia, give no guarantee of its avoidance.

The preoperative assessment of our patient, by two experienced practitioners, one in the pre-operative consultation clinic, the other in the immediate preoperative period outside the operating room, failed to reveal a difficult intubation. This is not unprecedented, as no clinical test or system of tests has proven completely sensitive or specific for the difficult or impossible laryngoscopic intubation. ${ }^{18,19}$

Ophthalmic surgery in our hospital is conducted in one of our standard operating rooms. Either monitored anaesthesia care during local anaesthesia, or general anaesthesia, is provided according to the Guidelines to the Practice of Anaesthesia of the Canadian Anaesthetists' Society, (1994). In particular, airway equipment includes laryngoscopes (with a variety of both straight and curved blades), endotracheal tubes, oropharyngeal and naso-pharyngeal airways, laryngeal mask airways, and malleable stylettes in each anaesthetic machine. Flexible fibreoptic bronchoscopes and "lightwands" are kept in a central location adjacent to our operating rooms.

In this case, there was careful pre-operative assessment, the operation was performed in an appropriately-supplied operating room, and the patient was closely monitored. The clinical diagnosis of brain-stem anaesthesia was made and initial treatment (support of ventilation and circulation as required $)^{20,21}$ carried out immediately. Despite these precautions, the patient became hypoxaemic and, because of unanticipated difficult intubation, was exposed to the same risks as any apneic, anaesthetized patient whose trachea cannot be intubated laryngoscopically ie., gastric distention, regurgitation and aspiration. ${ }^{22}$

Ventilation by mask proved to be easy in our patient, and the readily available laryngeal mask airway was selected initially to allow positive pressure ventilation while the decision was made whether tracheal intubation would be necessary for the brief apnea that was expected for brain stem anaesthesia ( $20 \mathrm{~min}$ - several hours). The leaking cuff on the laryngeal mask airway encouraged a traditional method of positive pressure ventilation in the operating room - the endotracheal tube. However, the unsuspected airway anatomy, making laryngoscopic intubation impossible, shifted our judgement back to the relatively easy, rapid laryngeal mask airway. In the event, ventilation was easy and effective, with no evidence of leak, gastric distention or regurgitation on insertion of the second laryngeal mask airway. Since the patient was fasted, was not obese, and had no known gastro-oesophageal pathology, and ventilatory pressures $<20 \mathrm{~cm} \mathrm{H}_{2} \mathrm{O}$ were required, we considered it safe to continue using the laryngeal mask airway. ${ }^{23}$

Our patient was adequately resuscitated and the lungs were ventilated by mask and oropharyngeal airway (or larngeal mask airway). However, in our opinion, a patient who is iatrogenically apnoeic for "minutes to hours"20 should not have to depend on mask ventilation, even if they have a "difficult airway." As personnel and equipment are required to manage rare complications of anaesthesia such as brain-stem anaesthesia as part of managed anaesthesia care, it should be recognised that these complications may also be associated with another rare complication unpredicted difficult intubation.

The case highlights the importance of adherence to guidelines for MAC in ophthalmic anaesthesia. It demonstrates that safe anaesthetic practice during $M A C$ requires readiness, not only for the management of apnea, but also for management of apnea in the presence of an unexpectedly difficult or impossible intubation. ${ }^{18,19}$ This may have implications for Monitored Anaesthesia Care in locations outside the hospital operating room (eg., endoscopy suites, emergency departments, office-based operating suites, etc.), where procedures are carried out under heavy sedation or general anaesthesia. ${ }^{24}$

\section{Acknowledgment}

The authors wish to thank Ms. Josephine Sham for the secretarial assistance.

\section{References}

1 Hamilton RC, Gimbel HV, Strunin L. Regional anaesthesia for 12,000 cataract extraction and intraocular lens implantation procedures. Can J Anaesth 1988; 35: 615-23.

2 Mallampati SR, Gatt SP, Gugino $L D$, et al. A clinical sign to predict difficult tracheal intubation: a prospective study. Can Anaesth Soc J 1985; 32: 429-34.

3 Samsoon GLT, roung JRB. Difficult tracheal intubation: a retrospective study. Anaesthesia 1987; 42: 487-90.

4 Tham EJ, Gildersleve $C D$, Sanders $L D$, Mapleson $W W$, Vaughan RS. Effects of posture, phonation and observer on Mallampati classification. Br J Anaesth 1992;68: 32-8.

5 Lewis $M$, Keramati S, Benumof $J$, Berry CC. What is the best way to determine oropharyngeal classification and mandibular space length to predict difficult laryngoscopy? Anesthesiology 1994; 81: 69-75.

6 Oates JDL, Oates PD, Pearsall FJ, McLeod AD, Howie JC. Phonation affects Mallampati class (Letter). Anaesthesia 1990; 45: 984. 
7 Aiello G, Metcalf I. Anaesthetic implications of temporomandibular joint disease. Can J Anaesth 1992; 39 : 610-6.

8 Bellhouse CP, Dore C. Criteria for estimating likelihood of difficulty of endotracheal intubation with the Macintosh laryngoscope. Anaesth Intensive Care 1988; 16: 329-37.

9 Calder I. Predicting difficult intubation (Letter). Anaesthesia 1992; 47: 528-9.

10 Youdas JW, Carey JR, Garrett TR. Reliability of measurements of cervical spine range of motion - comparison of three methods. Phys Ther 1991; 71: 98-106.

11 Chow FL, Duncan PG, Code WE, Tip RW. Can bedside neck extension predict difficult intubation? Can J Anaesth 1993; 40: A4.

12 Frerk $C M$. Predicting difficult intubation. Anaesthesia 1991; 46: 1005-8.

13 Nicoll JMV, Acharya PA, Ablen $K$, Baguneid $S$, Edge $K R$. Central nervous system complications after 6000 retrobulbar blocks. Anesth Analg 1987; 66: 1298-302.

14 Kobet KA. Cerebral spinal fluid recovery of lidocaine and bupivacaine following respiratory arrest subsequent to retrobulbar block. Ophthalmic Surg 1987; 18: 11-3.

15 Hamilton RC. Brain stem anesthesia following retrobulbar blockade. Anesthesiology 1985; 63: 688-90.

16 Unsold R, Stanley JA, DeGroot J. The CT-Topography of retrobulbar anesthesia. Anatomic-clinical correlation of complications and suggestion of a modified technique. Albrecht von Graefes Archiv fur Klinische und Experimentelle Ophthalmologie 1981; 217: 125-36.

17 Mandelcorn MS, Anantbanarayan C, Cole AFD, Rolbin $S H$. Brain-stem anesthesia following retrobulbar anesthesia: case report and possible pathophysiologic mechanism. Can J Ophthalmol 1996; 31: 24-6.

18 Bainton CR. Difficult intubation - what's the best test? (Editorial) Can J Anaesth 1996; 43: 541-3.

19 Karkouti $D$, Rose DK, Ferris LE, Wigglesworth $D F$, Meisami-Fard $T$, Lee $H$. Inter-observer reliability of ten tests used for predicting difficult tracheal intubation. Can J Anaesth 1996; 43: 554-9.

20 Troll GF. Regional ophthalmic anesthesia: safe techniques and avoidance of complications. J Clin Anesth $1995 ; 7$ : 163-72.

21 Nique TA, Bennett $C R$. Inadvertent brainstem anesthesia following extraoral trigeminal $\mathrm{V}_{2}-\mathrm{V}_{3}$ blocks. Oral Surg 1981; 51: 468-70.

22 Finucane BT, Santora AH. Principles of Airway Management, 2nd ed. St. Louis, MO: Mosby-Year Book Inc., 1996: 147.

23 Asai $T$, Morris $S$. The laryngeal mask aiway: its features, effects and role. Can J Anaesth 1994; 41: 930-60.

24 Cole AFD. Fibreoptic intubation. (Letter) Can J Anaesth 1993; 40: 469-70. 